\title{
A MEDIDA DA GORDURA. O INTERNO E O ÍNTIMO NA ACADEMIA DE GINÁSTICA
}

\author{
Carlos Emanuel Sautchuk
}

Naquele mesmo dia abandonou a academia. Irritou-se com o profesor, despediu-se das amigas e trancou a matrícula pensando em nunca mais voltar. "É demais!": há um ano ela se exercitava com um grupo de pessoas às 7 da manhã, montada sobre uma bicicleta estática, sob as instruções e a duvidosa seleção musical do professor e, quando resolveu fazer uma avaliação corporal, recebeu a notícia de que a gordura havia aumentado. Foi "o cúmulo!". Mas pior foi o professor que, ao interpretar um tanto surpreso os dados produzidos pelo computador, ao invés de mostrar solidariedade "fez foi tirar o corpo fora", lançando toda a culpa em suas costas. Aquele olhar de desconfiança e as perguntas, em tom irônico, a respeito de seu consumo de doces e chocolate foram a gota d'água. Perder a confiança do professor diante de um resultado negativo como aquele a levou a não prosseguir com a atividade. ${ }^{1}$

Compreensão de texto: quem são os agentes desse pequeno relato? Se levarmos em conta os participantes da trama dotados de capacidade de ação, então, além do professor e da aluna, a gordura deve ser considerada. É em vista dela que a aluna e o instrutor desempenham suas atividades e é em função de sua variação - o aumento inesperado - e seu caráter negativo que a situação se transforma e a relação se rompe.

Mas não pode haver nada de estranho em considerar a gordura como agente no mundo contemporâneo. Afinal, é de conhecimento público que ela é capaz de entupir uma artéria, tomar parte do orçamento nacional e habitar os piores pesadelos femininos. Sabe-se inclusive que ela pode ser masculina (tipo maçã, ou andróide) ou feminina (tipo pêra, ou ginóide) e que fica localizada ou espalhada pelo corpo. Sua forma de ação mais comum é através do peso. "Excesso", "massa supérflua", "sobrepeso", a gordura tem um efeito limitante sobre o corpo, tornando-o menos capaz: "Imagine você correndo com uma mochila de 10 quilos nas costas!", explica o freqüentador 
de uma academia de ginástica. Mas ela pode aparecer como um outro tipo de carga, aquela de um "peso na consciência". E ela é igualmente uma carga para a sociedade. Em seu manual sobre a obesidade, a Organização Mundial da Saúde preocupa-se com "o fardo econômico que eles [os obesos] impõem à comunidade", que se expressa na "perda de produção em função de ausência ao trabalho e morte prematura" (WHO 2000:78-9).

Como se vê, a gordura está articulada também à racionalidade econômica. Tanto assim que é possível obter sua cotação. Um estudo realizado em Boston estima que os programas de redução de peso custam até 23 dólares por quilograma (Spielman apud WHO 2000:94). E se há cotação, há mercado. Aliás, um grande mercado mundial de produtos e serviços direcionados ao combate da gordura, que envolve desde as editoras de livros e revistas sobre corpo, beleza e auto-ajuda até as confecções de roupas esportivas, mas principalmente as ações terapêuticas de combate à gordura.

Na investida contra a gordura, uma série de grupos busca posicionar-se como uma boa alternativa de consumo. Alguns endocrinologistas, associados a uma parte da indústria farmacêutica, opõem-se a outros médicos, que preferem indicar dietas alimentares e exercícios físicos. Estes, por sua vez, rivalizam com professores de educação física e nutricionistas, ciosos de seus monopólios profissionais sobre a atividade física e a alimentação. Todos eles, no entanto, unem-se nas trincheiras da ciência para combater o "charlatanismo" dos inventores de dietas e dos massagistas estéticos (que atacam a gordura com apertões, pancadinhas e deslizamentos de mãos) e o voluntarismo de pessoas que resolvem "queimar" gordura com "métodos caseiros", como correr ao sol envolto em sacos plásticos. Mas os combatentes populares não estão sozinhos, eles se associam à produção farmacêutica de vários portes e de diferentes matrizes lógicas - dos medicamentos sintéticos às preparações fitoterápicas oferecidas nas feiras, passando pela multidão de vendedores dos produtos Avon e Natura. Em contraste às investidas terapêuticas estão os cirurgiões bariátricos e os cirurgiões plásticos, propondo intervenções para redução do estômago e sucção da gordura (lipoaspiração) como soluções mais eficazes. E como em todo campo de disputa, há aqui um mínimo de convivência estabelecido por uma divisão provisória de espaços, definida quer pelo status socioeconômico da clientela, quer pelo montante de gordura a ser atacado.

Este panorama não é estranho às ciências sociais; a importância alcançada atualmente pelas práticas de modulação do corpo e o fato de que a gordura aparece como um de seus principais elementos é algo visitado a partir de diferentes perspectivas. Porém, no que se refere às práticas contemporâneas de modulação corporal, notadamente as empreendidas nas academias de ginástica, os estudos parecem negligenciar um aspecto importante ao 
apresentarem a gordura como sinônimo de corpulência, em oposição direta a um ideal de magreza. Este argumento é evocado em diferentes trabalhos, desde uma historiografia (Stearns 2002) ou uma pesquisa etnográfica (Castro 2003) abordando a coerção contemporânea em torno dos padrões corporais, até a análise sociológica de Fischler (1987 e 1995), que aponta no excesso de gordura corporal o signo da desarmonia entre alimentação e reciprocidade. Tais perspectivas, ainda que diferindo em seus objetos e conclusões, não concedem importância ao fato de que a gordura, tal como aparece nas práticas de modulação corporal, deriva de uma elaboração científica que situa seu campo de ação no interior do corpo. É a partir deste horizonte interno, e interagindo de uma forma distinta do peso ou da corpulência, que ela se coloca como um elemento central nas práticas corporais. ${ }^{2}$

E se nas academias de ginástica a gordura aparece sob múltiplas formas - componente orgânico, critério estético, risco à saúde ou ataque à auto-estima - é porque existem procedimentos capazes de traduzi-la de um modo a outro. Assim, passando ao largo da discussão sobre se a gordura é a causa biológica ou a conseqüência sociológica de certo "culto ao corpo" contemporâneo, este artigo busca apontar as formas de sua existência nas práticas corporais empreendidas nas academias de ginástica e como ela integra as concepções de corpo e de pessoa ali implicados.

\section{Avaliação da composição corporal ou como produzir gordura com um compasso de dobras cutâneas e uma equação}

Quando inicia suas atividades em uma academia de ginástica, e a partir de então periodicamente, o aluno é encorajado, quando não impelido, a passar por uma avaliação física. De qualquer modo, boa parte dos alunos busca realizar este exame como uma maneira de "ficar sabendo como está seu corpo", o que implica, sobretudo, "saber o tanto de gordura" nele contido. A avaliação feita em uma academia produz um dossiê, que traz em algumas páginas os resultados das medições realizadas. Ainda que algumas academias realizem outros exames, como o cálculo do consumo de oxigênio durante o exercício ou a análise da postura do aluno, a avaliação da composição corporal é o principal dos diagnósticos. O avaliador propõe a rotina de exercícios a partir destes números e trata de interpretar seus resultados para o aluno. Tanto para a conversa com o aluno quanto para o plano de exercícios, o percentual de gordura do corpo é o fator mais importante.

Diante deste procedimento, uma questão se impõe: como é possível fazer a gordura emergir do interior do corpo na forma de um valor numérico? 
O desenrolar da avaliação corporal não parece ser nada muito complexo. Primeiro são conectados instrumentos ao corpo, que geram algumas informações: a balança estabelece o peso do corpo que está sobre ela e o compasso de dobras cutâneas mede a espessura das dobras da pele obtidas através de pequenos beliscões em alguns lugares do corpo. Depois, os dados são jogados em um ordenador de informações (uma equação matemática), normalmente estruturado em um programa de microcomputador; dali retorna o percentual de gordura contido no corpo, ou seu valor correspondente em quilogramas.

Mas terá realmente algum sentido essa prestidigitação científica? Como é possível que o professor de uma academia, como um anatomista virtual, seja capaz de realizar o escrutínio de um corpo com tão poucas ferramentas, extraindo da massa indiferenciada, compacta e viva, em uma cifra exata, a quantidade de gordura livre de qualquer outra coisa? É que se executam aqui algumas ações imperceptíveis ao espectador. O segredo do avaliador consiste em colocar em funcionamento, junto com os dados por ele obtidos, uma seqüência de outros experimentos, além de suposições, estimativas e concepções a respeito do corpo humano que estão reunidas nos ordenadores de informação. Portanto, para dar conta desse processo é preciso recorrer também a uma outra dimensão da avaliação, pela qual respondem autores como Michel Pollock e Dartagnan Guedes - pesquisadores que, a partir de laboratórios no Texas ou no interior do Rio Grande do Sul, dedicaram-se à laboriosa tarefa de produzir fórmulas matemáticas empregadas na avaliação da composição corporal. A conexão entre os cientistas e os avaliadores se dá por meio dos manuais de avaliação corporal, utilizados nos cursos de formação em avaliação antropométrica. No Brasil, entre as publicações mais difundidas estão as de Pollock et alii (1986), Guedes (1994) e Heyward e Stolarczyk (2000).

Deve se começar dizendo que há um método direto para a obtenção da composição corporal. Ele consiste em realizar a dissecção minuciosa de um cadáver, colocando em pratos de balança o tecido adiposo, o tecido muscular, os ossos e o resto (órgãos, pele, sangue, vias nervosas, cérebro, veias, artérias...) (Guedes 1994:4; Pollock et alii 1986:215). Este é o método aceito como o mais exato para a obtenção de dados a respeito da composição anatômica do corpo humano ou animal, apesar de incrivelmente trabalhoso e com complicações éticas e técnicas (o que impede a inclusão de uma grande quantidade de sujeitos em uma pesquisa) e, ainda, que ele se valha da arriscada suposição de que o corpo morto é representativo do corpo vivo. Para os objetivos de diagnosticar e de prescrever dietas e exercícios, porém, esse método não é interessante, dada a sua incompatibilidade com a idéia de uma intervenção terapêutica posterior. 
Para medir a composição do corpo em vida criaram-se outros métodos. Eles são chamados indiretos justamente porque tomam como ponto de apoio o método direto, de dissecção. O método indireto mais utilizado é chamado de densitometria, pois opera com a densidade do corpo. Ao modelo do corpo em dois componentes - a gordura e o resto - articula-se o princípio básico de que a densidade da gordura é menor que a do resto do corpo; assim, quanto menor a densidade do corpo avaliado como um todo, maior a quantidade de gordura. A passagem densidade do corpo $\rightarrow$ quantidade de gordura é então quantificada em uma equação a partir dessa mesma relação em cadáveres, pois no corpo morto é possível saber a quantidade de gordura e também a densidade de cada tecido. Tendo esses dados como base, pode se estabelecer uma correlação entre a densidade total e a quantidade de gordura do cadáver fresco e generalizá-la para os corpos vivos. Nesse passo, há um pressuposto importante: as densidades da gordura e do resto do corpo são conhecidas e constantes. Pressuposto este que, por sua vez, contém outro: os componentes (água, minerais e proteínas) das outras partes corporais e da gordura não sofrem variações de um momento a outro ou entre indivíduos (Guedes e Guedes 1998:80; Heyward e Stolarczyk 2000:9).

Obtem-se, então, a fórmula para transformação da densidade do corpo em quantidade de gordura ${ }^{3}$, mas para utilizá-la in vivo é preciso antes saber a densidade total da pessoa avaliada. Se a densidade é obtida dividindo-se o peso pelo volume, e o peso é facilmente obtido com uma balança, o problema é saber o volume do corpo avaliado para conectá-lo a todo o cálculo já preparado. Ao lançar mão de alguns princípios da física dos fluidos, obtém-se o volume do corpo por meio da diferença entre o peso do avaliado fora e dentro d'água (mensurado em um tanque com uma balança submersa).

Há uma peculiaridade nesse cálculo do volume corporal que nos obriga a uma outra estimativa. É o fato de permanecerem gases no trato gastrointestinal e também nos pulmões, mesmo que o sujeito avaliado se esforce empreendendo uma dieta na véspera e executando uma expiração máxima antes de imergir na balança subaquática. Esses gases dificultam a relação direta do corpo submerso com as equações que expressam as leis da física, pois o fazem flutuar. Para fazer valer essas leis, os gases que permanecem nas vias aéreas são mensurados, os do aparelho gastrointestinal estimados e ambos são subtraídos do cálculo (Pollock et alii 1986:216).

Pronto, por meio dessa série de transfomações (peso do corpo submerso $\rightarrow$ densidade do corpo $\rightarrow$ quantidade de gordura) é possível obter o peso que a gordura exerce sobre um corpo sem que haja necessidade de abri-lo. Basta que academias, consultórios e demais interessados construam um tanque de pesagem hidrostática, com uma balança submersa, um controle cuidadoso 
da temperatura e da qualidade da água e que os sujeitos avaliados realizem uma dieta preparativa e se disponham a submergir e a ficar imóveis algumas vezes. Mas tal laboratório é muito custoso e complexo para que seja difundido (Guedes 1994:81; Pollock et alii 1986:210). E se as verdades produzidas pela ciência tornam-se universais apenas através da rede de laboratórios que as sustenta e que as faz funcionar (Canguilhem 2002 [1966]:114; Latour 1994:226), então haveria aqui o risco de que esta nova produção científica a gordura - estendesse sua ação a poucos lugares.

Latour avisa, porém, que a ciência tem uma outra máxima importante: "se você não vai ao laboratório, o laboratório irá até você" (Latour 1993:157). Mas para que o laboratório vá até onde é preciso, para que ele amplie o alcance da tradução de volume corporal em densidade e desta em quantidade de gordura, é preciso simplificá-lo, tornando-o mais barato e menos complexo tecnicamente. Isto se faz aumentando a concentração de conhecimentos em alguns atos, com o preço de acentuar ainda mais "a séria desvantagem [do laboratório] de confiar na infinita sedimentação de outras disciplinas, instrumentos, linguagens e práticas" (Latour 2001:46).

A solução encontrada - que, como explica o antropometrista brasileiro Dartagnan Pinto Guedes, tornou o método menos "custoso" e "sofisticado" (Guedes 1994:88) — foi a seguinte: reduziu-se o laboratório a um compasso de dobras cutâneas, também chamado adipômetro, e a uma equação, além, é claro, de um técnico capacitado nos procedimentos. Algo simples, rápido e barato, que um médico ou um nutricionista pode manejar durante sua consulta e um professor de educação física pode obter para a sua academia. Tal concentração do laboratório equivale à adição de mais um elo à cadeia de transformações já estabelecida.

O novo elo é chamado de método duplamente indireto, pois apóia-se no método indireto da densitometria. Ele consiste em uma equação que transforma a nova medida - a dobra cutânea — no parâmetro que se conecta ao cálculo estabelecido anteriormente - a densidade corporal. Essa equação é chamada de regressiva, pois faz o caminho inverso daquele através do qual foi criada-descoberta. Ela é estabelecida do seguinte modo: submete-se um grupo de pessoas ao procedimento da densitometria, obtendo daí sua densidade corporal (como vimos anteriormente). Depois, mede-se a espessura das dobras cutâneas em alguns pontos do corpo e cria-se uma fórmula que relacione os valores das dobras cutâneas com números fixos (os índices), de tal forma que o resultado da operação matemática seja o mesmo que o cálculo da densitometria havia indicado. Faz-se uma série de testes com outras pessoas, para garantir que o nível de erro da fórmula em relação à densitometria seja o menor possível. A partir daí, ao colocarmos os valores 
das dobras cutâneas de qualquer pessoa na fórmula, obteremos a densidade corporal e desta teremos, por fim, a quantidade de gordura. ${ }^{4}$

O elo das dobras cutâneas acrescenta mais alguns pressupostos e outras tantas estimativas à cadeia. Pressupõe-se que a gordura que fica sob a pele nos locais medidos é representativa da gordura total, isto é, mantém com ela uma relação sempre na mesma proporção; que as variações momentâneas de hidratação do tecido subcutâneo são irrelevantes para a medida de sua espessura; e que a habilidade do avaliador e a calibragem do compasso não influenciam nas medidas (Guedes 1994:49-50; Heyward e Stolarczyk 2000:24-5). Todo esse processo pode ser esquematizado como no quadro 1.

Quadro 1 - Cadeia de traduções da gordura

\begin{tabular}{|c|c|c|c|c|c|}
\hline \multirow[t]{2}{*}{ Método $\Rightarrow$} & & DIRETO & INDIRETO & $\begin{array}{l}\text { DUPLAMENTE } \\
\text { INDIRETO }\end{array}$ & \\
\hline & $\begin{array}{l}\text { MICRONÍVEL } \\
\text { (CELULAR, MOLECULAR } \\
\text { ATÔMICO) }\end{array}$ & $\underset{\text { DE CADÁVER }}{\text { DISSECCÃO }} \leadsto$ & $\underset{\text { HIDROSTÁTICA }}{\text { PESAGEM }} \leadsto$ & $\begin{array}{l}\text { MEDIDAS } \\
\text { DE DOBRAS } \\
\text { CUTÂNEAS }\end{array}$ & $\begin{array}{l}\text { PRÁTICAS } \\
\text { DE SAÚDE } \\
\text { E BELEZA }\end{array}$ \\
\hline $\begin{array}{l}\text { Pressupostos } \\
\text { e estimativas }\end{array}$ & $\mathrm{s} \Rightarrow$ & $\begin{array}{l}\text { o corpo morto } \\
\text { equivale ao } \\
\text { vivo }\end{array}$ & $\begin{array}{l}\text { a densidade } \\
\text { estimada da } \\
\text { gordura e da } \\
\text { massa magra é } \\
\text { constante, assim } \\
\text { como a proporção } \\
\text { de seus } \\
\text { componentes } \\
\text { (água, minerais, } \\
\text { proteínas. } \\
\text { é estimado o } \\
\text { volume de gases } \\
\text { que permanece } \\
\text { no trato gastro- } \\
\text { intestinal e nos } \\
\text { pulmões após } \\
\text { a expiração } \\
\text { forçada. }\end{array}$ & $\begin{array}{l}\text { a gordura } \\
\text { subcutânea e } \\
\text { a gordura total } \\
\text { mantêm sempre } \\
\text { uma relação } \\
\text { proporcional. } \\
\text { a hidratação } \\
\text { não interfere na } \\
\text { espessura das } \\
\text { dobras cutâneas. } \\
\text { as variações nas } \\
\text { aplicaços de } \\
\text { medição e na da } \\
\text { calibragem do } \\
\text { compasso são } \\
\text { irrelevantes. }\end{array}$ & \\
\hline
\end{tabular}

A gordura não é o que resulta dessa seqüência de operações, mas o que estende sua presença a cada um dos níveis intercomunicados. Quer dizer, a gordura desdobra-se ao longo dessa cadeia, sempre se originando de algo e ganhando outra configuração. É por isso que se pode falar da forma como se apresentam as ligações do carbono em determinado lipídio, da flutuabilidade do tecido adiposo ou do máximo de volume e rugosidade tolerável nas pernas femininas tratando sempre da mesma coisa.

Contudo, para funcionar plenamente, essa cadeia precisa manter seus elos bem alinhados e disciplinados. Cada um deve remeter diretamente ao outro e sem emperrar a comunicação. Quando, por exemplo, um avaliador se atrapalha na mensuração das dobras cutâneas, a cadeia é bloqueada e não 
A MEDIDA DA GORDURA

há mais relação entre a silhueta de sua cliente e as células adiposas. Além de manter o alinhamento, a cadeia não deve ser interrompida em nenhum sentido. De um lado, seguem as transformações em tecidos, células, moléculas, átomos; de outro, a gordura em forma de signo matemático continua sua trilha, traduzindo-se em novos índices, prescrições de exercícios físicos, cálculos de dietas alimentares, aflições íntimas, ímpetos de mudança, sensações de vitória, crises depressivas, prejuízo e lucro econômico e tudo o mais que deriva da articulação entre a gordura e as concepções a respeito da beleza e da saúde.

Ao se deparar com esta série de desdobramentos, o leitor poderia perguntar se no âmbito das práticas corporais orientadas em função da gordura não existiriam formas cotidianas de identificá-la, que não recorressem à avaliação antropométrica tal qual descrita. Sem dúvida, elas existem e são amplamente utilizadas. Porém, mesmo os diagnósticos "leigos" funcionam através de uma referência subjacente às formas "científicas" de produção da gordura. Ou melhor, as análises rotineiras não se opõem, mas atuam conectadas ao saber antropométrico. Quando alguém não consegue mais abotoar uma calça, percebe um aumento no mostrador da balança da farmácia ou recebe um comentário maldoso, está coletando indícios de que algo se transforma internamente. "Quando eu vim pra academia, eu já sabia que estava meio gorduroso", diz um aluno após sua primeira avaliação.

Por outro lado, a avaliação antropométrica (que uma pessoa realiza quando muito três ou quatro vezes ao ano em academias ou consultórios) não pode estender sua eficácia à evolução diária das práticas de exercícios ou dietas sem que existam formas prosaicas de avaliação, como o espelho, a balança, o cinto e a opinião alheia. Em uma palavra, a avaliação da composição corporal e as formas cotidianas de análise do corpo estão vinculadas, porque ambas guardam o mesmo princípio de remeter as dimensões exteriores ou a apreciação global do corpo a seus conteúdos. A partir deste princípio, emergem os elementos principais das práticas de saúde e beleza o músculo e a gordura - que habitam o interior do corpo.

\section{Dimensões e conteúdos}

Como podemos observar no quadro 1, a produção da gordura se estabelece através de uma seqüência de operações na qual é possível identificar fragilidades importantes. Este é um problema explicitado no interior da antropometria e não é difícil encontrar especialistas ou mesmo avaliadores nas academias que lancem suspeitas sobre a legitimidade desta seqüência de traduções, referindo-se aos aspectos citados no quadro 1. Além disso, 
alguns dizem que seu uso deveria se restringir a uma parcela da população, biologicamente semelhante àquela que serviu ao estabelecimento das equações. Outros rejeitam o cálculo da percentagem de gordura, alegando que ele está fundado em um "corpo de referência" fictício, que representa um adulto de 25 anos nos Estados Unidos. Há ainda os que lamentam a larga margem de erro deste cálculo, que seria grande o bastante para torná-lo inútil no monitoramento de um plano de treinamento. É bem verdade que tais opiniões são isoladas e que o método tem ampla credibilidade nas academias. Mas o fato de que essas críticas sejam a um só tempo pertinentes (segundo a própria lógica da avaliação) e ineficazes, leva-nos a perguntar pelos pontos de sustentação da cadeia capazes de estenderem a legitimidade dos procedimentos de produção da gordura.

Um professor de academia segredou-me certa vez que desconfiava da validade do cálculo da porcentagem de gordura corporal, mas que terminava por se conformar: "na academia eu tenho que fazer; o cliente quer saber uma quantidade [de gordura], se está bom ou não!". De fato, o conjunto das práticas de modulação do corpo nas academias de ginástica funciona com base em um saber-fazer sobre o interior do organismo. Objetivos e estratégias são fixados em termos de uma diminuição da quantidade de gordura e/ou do aumento do volume de uma parte da musculatura. As atividades são realizadas tendo em vista músculos específicos: os cartazes que ilustram as posições de alongamento e os vários exercícios de musculação identificam a musculatura empregada. As máquinas de musculação são nomeadas conforme o grupo muscular que elas são capazes de ativar. As conversas entre os alunos e as orientações dos professores são permeadas de termos anatômicos, como bíceps, deltóide e dorsal. Nos "exercícios aeróbicos" (na esteira rolante ou na bicicleta ergométrica), o praticante conduz a atividade tendo em vista seu metabolismo energético, com base nos dispositivos eletrônicos que mostram os batimentos cardíacos e a estimativa do consumo de calorias. A "ginástica localizada" dirige-se às partes do corpo nas quais a relação entre a gordura e o músculo é particularmente desfavorável. Em suma, entre estas práticas e o saber antropométrico existe um mesmo conjunto de referências sobre o interior do corpo, em que interagem alguns termos: músculo, caloria, massa magra, gordura.

Se a avaliação da composição corporal é uma forma de engajar os componentes internos em uma prática corporal, isto ocorre porque avaliação e prática articulam-se através de alguns pontos estruturantes, que sustentam a produção e a circulação da gordura. Para indicá-los, voltemos a atenção para alguns textos fundamentais para o desenvolvimento da antropometria contemporânea. O objetivo aqui não é ignorar a decalagem entre o estabele- 
cimento da avaliação da composição corporal como método antropométrico e sua utilização nas academias de ginástica, mas identificar os fundamentos da concepção de corpo que informam tanto os manuais de avaliação corporal, quanto o cotidiano das academias. Estes fundamentos remetem a um modo particular de relacionar características exteriores e conteúdos do corpo, e ganham forma na transformação de princípios e métodos por que passou a antropometria em meados do século XX.

Um novo modo de utilização das medidas corporais foi apresentado em dois experimentos realizados por uma dupla de pesquisadores que pertenciam, na década de 1950, ao Laboratório de Higiene Fisiológica da Universidade de Minesota. As proposições de Josef Brozek e Ancel Keys ${ }^{5}$ estabelecem os princípios e os métodos que compõem atualmente a avaliação da composição corporal (como a densitometria e as dobras cutâneas), e seus trabalhos são evocados como fundamento dos textos contemporâneos sobre avaliação da composição corporal. ${ }^{6}$ Não é minha intenção, porém, contribuir para a história da antropometria, mas sim identificar os termos de uma inflexão no que concerne à concepção do corpo e ao seu funcionamento, termos estes sustentados por Brozek e Keys, com proposições que se repetem nos manuais de avaliação corporal, no contexto das academias de ginástica e nas revistas dedicadas à saúde e à estética.

Vejamos os dois experimentos. O primeiro dá conta de que o estatuto do corpo, em especial sua saúde, depende do balanço de seus conteúdos, que podem ser reduzidos a um modelo de dois componentes: gordura e massa magra (músculos, ossos, vísceras etc.). Planejado para contrapor o argumento de que o peso do indivíduo poderia ser tomado como parâmetro de saúde, o experimento é publicado na revista Science, em artigo intitulado "Limitações do peso corporal 'normal' como critério de normalidade" (Brozek e Keys 1950). Os autores voltam-se especialmente contra as tabelas de peso ideal elaboradas desde o final do século XIX por empresas que comercializavam seguros de vida. Essas tabelas, apresentando valores médios da população estadunidense, foram concebidas como referência para o cálculo do preço da apólice dos indivíduos com base em seu risco de morte, e expandiram-se na prática médica durante a primeira metade do século XX, instrumentalizando a relação peso-mortalidade ou peso-saúde (Keys e Brozek 1953:252; cf. Stearns 2002:114).

O experimento consistia em comparar a composição corporal de dois grupos de homens com idades diferentes - um de 19 a 25 anos e o outro de 45 a 55 - e chegou à seguinte conclusão:

[...] embora ambos os grupos sejam "normais" quanto ao peso corporal, eles 
diferem notadamente em termos de composição do corpo. [...] O conceito de peso corporal "normal" [...] tende a obscurecer as transformações profundas que têm lugar no processo de envelhecimento. Este envolve não somente uma acumulação progressiva de gordura corporal mas também, muito provavelmente, substituição de uma parte de músculos (e outros "tecidos ativos") por tecidos gordos (Brozek e Keys 1950:788).

Assim, não apenas as tabelas de peso ideal estariam equivocadas, mas também outras qualificações do corpo a partir de uma apreciação global, como os diversos usos antropométricos da relação peso/altura e a noção de corpulência. Ao não discriminarem os conteúdos corporais, estas mensurações do corpo negligenciariam os verdadeiros determinantes da "predisposição à doença" (Keys e Brozek 1953:246).

Mais importante a observar, entretanto, é que a crítica aos métodos antropométricos não implica rejeição à mensuração das dimensões do corpo, mas sua utilização em outro sentido. Peso, altura, circunferência dos membros e espessura do tecido adiposo são tomados por esses autores de outra maneira: como forma de identificar os conteúdos internos do corpo. O melhor exemplo disto é o restabelecimento da legitimidade do peso e da altura como indicadores de risco à saúde, expresso no índice de massa corpórea, o hoje célebre IMC. Durante a primeira metade do século XX, a utilização da relação peso-altura ganhou várias formas que se desdobraram principalmente a partir de Adolph Quetelet (1870) (que encontrou ali a expressão da regularidade do desenvolvimento humano ideal) e do indice ponderale, proposto por Carlo Livi (1897) como um padrão de referência para que a antropologia física pudesse comparar inúmeras coisas, como o volume do cérebro.

Inicialmente, Keys e Brozek (1953) criticaram a utilização que antropometristas e antropólogos físicos faziam destas duas medidas, duvidando que elas pudessem oferecer informações sobre os conteúdos corporais. Entretanto, quase duas décadas depois, Keys e um grupo de colaboradores restabeleceriam a validade da relação entre peso e altura, batizando-a de IMC (Keys et alii 1971). A equação peso $\div$ altura $^{2}$ se reabilita através de um novo experimento, que a revitaliza por meio de outra premissa orientadora: mostrar sua relação com a gordura corporal. O experimento conclui que nos diferentes grupos estudados o IMC reflete significativamente a variação das medições da gordura, portanto, ele funciona como seu indicativo. Assim, o índice é acrescentado como mais um elo no quadro 1, de tal forma que com apenas dois dados - altura e peso - é possível conectar a pessoa à cadeia da gordura. Celebrizado como forma de obter rapidamente uma indicação sobre 
a quantidade de gordura corporal, sobretudo em estudos epidemiológicos (e.g. WHO 1995, 2000), o IMC é também transposto para o uso individual em revistas, em páginas de Internet ou em cartazes nas balanças das farmácias, por meio de interpelações como "saiba se está gordo" ou "confira se deve emagrecer". A reabilitação da relação peso-altura como avaliação do corpo opera-se justamente porque ela passa a remeter ao seu interior, formando um novo elo na cadeia de traduções da gordura representada no quadro $1 .{ }^{7}$

Mas a este primeiro ponto - o estatuto do corpo reside em seus conteúdos - Brozek e Keys articulariam outro: os componentes do corpo formam um sistema metabólico, sujeito à prática de uma "higiene fisiológica" (Keys e Brozek 1953:246). No segundo artigo publicado na Science (Brozek e Keys 1952), eles apresentam um experimento destinado a mostrar que a composição interna do corpo é passível de transformação. O alvo das críticas é a teoria dos "somatótipos" de William Sheldon (1940), que propõe a existência de três tipos físicos - endomorfo, mesomorfo e ectomorfo — tidos como o resultado da relação entre os diferentes tecidos que constituem o corpo de um indivíduo desde a sua geração. Além de reprovarem o fato de que o sistema de Sheldon referia-se a componentes corporais não exatamente "anatômicos" (e que não conferia privilégio à medição da gordura), Brozek e Keys lamentam que ele tenha sido "[...] proposto originalmente como um meio de descrever o tipo corporal como um todo, concebido como normalmente fixo, com características constitucionais" (1952:140). Para demonstrar que a constituição corporal é multifacetada e passível de alteração, eles realizam um experimento que consiste em levar um grupo de pessoas a diminuir em um quarto seu peso corporal, realizando antes e após esta redução a avaliação do somatótipo de Sheldon e a medição da quantidade de gordura. Ambos os parâmetros acusaram variações significativas, o que sustenta duas conclusões: 1. o tipo corporal é passível de transformação; 2. o elemento mais significativo nessas transformações é a gordura.

Tanto a noção de peso-padrão quanto a teoria dos somatótipos de Sheldon são tomadas como alvos dos experimentos de Brozek e Keys não apenas porque evidenciam suas idéias através de um contraste. Cada uma delas apresenta também um importante fator a ser incorporado (com um novo sentido). Das tabelas de peso-padrão, Brozek e Keys retêm a ligação entre o risco à saúde e a compleição corporal, ainda que esta seja transposta do peso ao balanço dos conteúdos corporais. De Sheldon é tomada a proposta de uma caracterização do indivíduo baseada nos componentes corporais, ainda que os componentes sejam outros e passíveis de transformação.

Em suma, a partir destes termos - o risco e a maleabilidade — Brozek e Keys delineiam um "sistema de análise corporal focado no metabolismo 
energético total", no qual figuram dois componentes corporais básicos: uma parte "ativa", composta pela musculatura, e uma parte "relativamente inerte", em que tem lugar a gordura (Keys e Brozek 1953:246). Os outros conteúdos anatômicos - ossos, vísceras, pele, cérebro etc. - ficam em segundo plano neste sistema, podendo ser agrupados com a musculatura, de modo que a gordura permaneça isolada e se torne possível verificar a amplitude particular de sua variação. A importância da musculatura e da gordura neste modelo fica expressa no papel que elas desempenham nos processos básicos do metabolismo corporal - a formação (anabolismo) e a degradação (catabolismo). E os principais vetores de transformação corporal são o aporte e o gasto energético (alimentação e atividade física).

Os textos de Brozek e Keys estabelecem um quadro particular de noções sobre o corpo, que eles cuidam bem de diferenciar das que foram defendidas por outros antropometristas ou antropólogos físicos. Nesse horizonte de preocupações - articuladas em torno do que podemos chamar de corpo-metabolismo - a medição não se volta à revelação das dimensões ideais do homem, como queria Quetelet (1870), ou à determinação dos parâmetros distintivos das raças e dos indivíduos, como foi o projeto de uma certa antropologia física. Está longe também das preocupações com a "eficiência física", que interessa sobretudo no âmbito de um corpo envolvido no processo de trabalho (Matiegka 1921). Nem tipo ideal, nem prova da variedade da espécie, nem valência diante das coisas: no corpo-metabolismo as dimensões exteriores revelam conteúdos que formam um sistema de transformações suscetível ao "desenvolvimento de uma higiene fisiológica" (Keys e Brozek 1953:307).

\section{Beleza interior}

Já foi dito que o sistema metabólico de dois componentes informa não apenas os métodos antropométricos, mas também as práticas de exercícios e as percepções do corpo na academia de ginástica. Porém, seria equivocado reduzir tudo isto às proposições de Brozek e Keys. Antes de mais nada, seus textos não tratam de um aspecto extremamente importante, que são os desdobramentos do corpo-metabolismo na percepção e na valoração das formas corporais. É bem verdade que eles não deixam de apontar tais influências: "O balanço destes dois conteúdos [ativos e inertes] determina em grande parte a conformação externa e a aparência do corpo assim como tem efeitos profundos na personalidade e no quadro emocional [...]" (Keys e Brozek 1953:246). Mas sua proposta é quantificar o metabolismo corporal geral, 
com o intuito de subsidiar uma epidemiologia e uma higiene fisiológica, passando assim ao largo de uma apreciação detalhada da forma.

Para tratar deste aspecto, voltemos nossa atenção ainda uma vez para o desenrolar da avaliação corporal nas academias de ginástica, onde observamos no centro dos procedimentos o compasso de dobras cutâneas ou adipômetro. A utilização do adipômetro nas academias tem duas dimensões coordenadas, das quais é preciso notar as especificidades. Uma de suas propriedades é aquela, já abordada, de traduzir a medição da espessura da gordura subcutânea em uma quantificação do metabolismo corporal. Quando propõem esta operação, Brozek e Keys comentam o uso rudimentar que médicos e antropometristas faziam do adipômetro anteriormente, vendo nisto uma subutilização das possibilidades do instrumento (Keys e Brosek 1953:257). ${ }^{8}$

Em alguns casos, porém, a utilização do adipômetro exprime intenção outra que a objetificação do metabolismo. Quando Paul Richer dedicavase, no final do século XIX, a desenvolver compassos para medir a gordura subcutânea (1890:258), seu objetivo não era quantificar o total de gordura. Ao medir a espessura das dobras cutâneas, ele não aspirava avaliar o interior do corpo, mas sua forma. Richer utiliza o "compasso de espessura" para verificar "a parte considerável que cabe ao tecido adiposo na conformação exterior", advertindo que "ele intervêm [...] não apenas à maneira de um véu atenuando os contrastes do écorché [ilustração da anatomia dos músculos], mas como fator direto da forma, do mesmo modo que os músculos e os ossos" (Richer 1890:23). O compasso de Richer apresenta então uma outra capacidade - verificar a distribuição da gordura pelo corpo - que viria a ser utilizada, por exemplo, no modelo de caracterização das formas corporais masculinas (andróides) e femininas (ginóides), de acordo com a "topografia" do tecido adiposo (cf. Vague 1947).

Na academia de ginástica, o compasso também é utilizado para mostrar as peculiaridades de cada parte do corpo, indicando os lugares onde a gordura se acumula, exercendo influência decisiva sobre a forma. Mas a relação da gordura com o contorno e a consistência do corpo toma aqui outro valor, longe da equidade com músculos e ossos que lhe garantia Richer. De qualquer modo, durante a avaliação corporal, enquanto são colhidos os dados para compor as equações, o compasso produz este outro tipo de informação, que o avaliado segue com apreensão: "vendo todos os lugares onde [o compasso] apertou, eu me assustei; não imaginava que eu tinha tanta gordura no meu corpo!". Esta outra direção na qual se desdobra a medição da dobra cutânea na academia de ginástica — qualificando as partes do corpo — não apenas se desenrola simultaneamente ao cálculo dos componentes metabólicos, como 
compartilha seus termos. Afinal, os processos (anabolismo e catabolismo) e os componentes (músculo e gordura) do metabolismo são os determinantes da forma corporal e os agentes de sua transformação.

Assim, a forma corporal também se reporta ao interior do corpo, quer dizer, a modulação corporal não resulta do controle do volume ou do peso corporal enquanto tais, mas de um manejo dos elementos internos. É certo que o emagrecimento ou a perda de peso são processos sempre evocados, mas apenas na medida em que eles implicam uma diminuição da quantidade de gordura do corpo. A preocupação com o peso transfere-se ao domínio interno, onde a gordura contrasta com a massa ativa do corpo, identificada na musculatura. Esta é a linha geral da publicidade das academias de ginástica, que oferece antes de mais nada "redução da gordura corporal" e "hipertrofia muscular". Justamente porque as dimensões e a forma do corpo remetem ao seu interior é que a avaliação da composição corporal pode ser reveladora da aparência: "fisicamente eu não estava vendo nada, mas como havia muita gordura onde tinha massa, eu me assustei, achei horrível!".

Portanto, o argumento de que a rejeição à gordura encontra explicação no estabelecimento da "magreza como valor moral" (Fischler 1987:275) não parece exato no contexto aqui analisado. A menos que se compreenda a magreza em um outro sentido - ausência de gordura, e não, pouco peso ou corpo menos volumoso. Os manuais de antropometria não hesitam em distinguir: "há uma importante diferença entre ser leve e ser magro" (Heyward e Stolarczyk 2000:3). Os professores de academia mostram isso a seus alunos com exemplos práticos, fazendo-os notar que a perda de gordura pode ocorrer simultaneamente ao aumento do peso, em decorrência do desenvolvimento da musculatura, considerada "massa magra". Enfim, como evidência definitiva de que a magreza (como qualificação geral do corpo) não é um objetivo das práticas de modulação corporal, lembremos do grande contingente de "magros" inscritos nas academias em busca de um corpo mais volumoso.

Para apontar um "ideal estético" que responda pelas transformações do corpo praticadas nas academias de ginástica é necessário procurá-lo na proporção dos componentes internos - "mais músculos, menos gordura", resume a manchete da revista Boa Forma.${ }^{9}$ Este balanço interno ideal corresponde ao "corpo definido", com pouca gordura superficial, em que se pode visualizar os feixes musculares. Expressão da proporção interior na aparência corporal, a definição é alcançada através do desenvolvimento da musculatura e do consumo da gordura corporal, processos metabólicos que orientam as práticas corporais. A percepção da definição funciona com base nos signos que se apresentam na superfície corporal, através dos quais a gordura é 
identificada — flacidez, ondulação, rugosidade, volume. Em contrapartida, a diminuição da gordura faz emergir a estrutura muscular e suas características - lisura e solidez. Nessa lógica das qualidades sensíveis expressa nos corpos das academias, o rígido, o duro, o tenso (seco) deve predominar sobre o suave, o tenro, o mole (úmido). Tanto assim que são utilizadas as expressões "secar" ou "enxugar" ao se referirem aos exercícios capazes de inserir o corpo em um registro mais valorizado. ${ }^{10}$

Se a definição corporal é objetivo corriqueiro dos freqüentadores de academia, justificando inclusive as expectativas mais modestas ("eu só quero ficar um pouco mais definido..."), ela norteia também as intensas transformações corporais empreendidas pelo fisiculturista. Estereótipo do trabalho do corpo nas academias, figurando em anúncios, revistas e pôsteres, o fisiculturista leva ao paroxismo a produção da definição, e sua prática corporal aponta um estatuto particular do músculo. Encerrado na relação entre a forma e o interior, o músculo não indica capacidade diante das coisas - nem força, nem deslocamento. Diferente da prática esportiva de forma geral, nas academias de ginástica o músculo não é o vetor de uma ação, mas ele é, ao contrário, produto do movimento. Há uma espécie de inversão em relação aos estudos sobre o movimento na era industrial que, por intermédio de uma "economia do gesto", buscavam conciliar o máximo efeito do movimento com o mínimo de trabalho muscular (cf. Marey 1994 [1894] e Pociello 1999). Inversão notável nas próprias máquinas de musculação, que estruturam a posição e o gesto do executante buscando, ao mesmo tempo, a maximização do trabalho de um determinado grupo de músculos e a redução da manifestação espacial do movimento, componente estéril da atividade.

Nas competições de fisiculturismo, o objetivo das "poses" não é criar uma seqüência de posturas e deslocamentos no espaço - elas são um meio de otimizar o efeito da contração muscular e padronizar sua apresentação. O que está em disputa é justamente o conteúdo, e não o gesto; é o manejo dos componentes corporais que importa, tal qual ele salta à superfície, mostrando-se aos olhos..$^{11}$ É neste sentido que Arnold Schwarzenneger afirma que seu corpo é "dramático" (apud Fussel 1997:44): o que o fisiculturista apresenta, no palco e na rua, não é a possibilidade de ação (que, aliás, se restringe com a exacerbação do volume muscular), mas uma performance metabólica. Como observa Jean-Jacques Courtine, o corpo do fisiculturista não evoca força nem movimento:

[...] insólitas massas musculares, puramente decorativas, que não servem para correr, nem para arremessar, e que rompem assim com tudo aquilo que, dentro da 
lógica esportiva, associa músculo a movimento. Impressionantes afrontamentos em pesadas coreografias, duelos de imagens sem contato nem violência, puras lutas de aparência (Courtine 1995:83).

O fato de que o gesto não visa à ação, mas à forma corporal, revela por que o fisiculturismo causa espécie entre os adeptos dos valores clássicos do esporte (ao estilo Coubertin). Isto justificaria também o uso da designação "narcisismo", evocada freqüentemente para caracterizar as práticas corporais das academias. Todavia, existem ao menos duas reservas à utilização deste termo. Em primeiro lugar, o belo aqui remete ao "desenvolvimento" interno, derivado da sobreposição do músculo à gordura. Se há um prazer em ver e em mostrar o próprio corpo, ele não advém da contemplação e da vaidade diante de uma forma harmoniosa, mas está ligado à "satisfação" decorrente do aprimoramento constante da definição, seja ele fruto do aumento muscular provocado imediatamente pelo exercício, ou o resultado do último período de treinamento. A forma remete aos processos de produção e manutenção de um estado do metabolismo que tende sempre a regredir. Assim, mesmo se é da produção da aparência de que se trata, não é exato falar de superficialidade (nos sentidos físico e espiritual) — como veremos, o objetivo dessas práticas é uma mobilização da pessoa através dos conteúdos corporais.

Outra ressalva é que a prática corporal das academias não se resume à busca de uma forma "definida". Lembremos que nesse ambiente o fisiculturista é a uma só vez ícone e marginal. Expressão de uma estética do metabolismo, ele é radicalmente engajado na manipulação dos processos internos em prol da forma, com intensas rotinas de exercício e uma dieta que comporta o consumo de suplementos proteicos e diversas drogas. Mas justamente por praticar um manejo extremo do organismo, ele expressa também o desprezo à saúde. Esta dupla condição do fisiculturista revela os dois termos que orientam as práticas corporais nas academias de ginástica: centrado no cultivo do metabolismo, ele negligencia o balanço que deve existir entre a beleza da definição e a gerência dos riscos à saúde.

\section{0 interno e o íntimo}

Que conteúdos e propriedades corporais exprimam valores e orientem um conjunto de práticas não é de modo algum uma inovação das academias de ginástica. O mais breve panorama etnográfico mostraria que os elementos corporais são elaborados de diferentes modos, sejam eles princípios morais, propriedades constitutivas da pessoa, signos de uma influência maléfica etc. 
(p. ex. Polhemus 1978; CNRS 1981; Godelier e Panoff 1998; Héritier e Xanthakou 2004). Significativa é a maneira como esses elementos são elaborados em cada situação e o seu papel na configuração da pessoa. No caso da gordura, é preciso considerar o horizonte de elaboração do corpo e do indivíduo vinculados à anatomia moderna. Se Keys e Brozek iniciam Gordura corporal no homem adulto (1953) com uma citação de Hipócrates sobre os quatro humores, revisitando assim o tema dos conteúdos corporais, eles não deixam de apontar no surgimento da "anatomia 'exata'" e da "classificação quantitativa" a condição de existência de uma nova ordem de componentes, compreendidos em uma fisiologia particular do corpo humano (Brozek e Keys 1953:245).

E, como se sabe, a instituição do indivíduo moderno como ser dotado de um domínio psíquico singular articula-se a esta objetificação do interior do corpo (cf. Foucault 1972; Le Breton 1990 e Gil 1997). De um lado, este quadro remete a verdade do indivíduo ao seu domínio íntimo, fator que pôde se desdobrar, de acordo com Luiz Fernando D. Duarte, em uma leitura de si por via da "experiência" e da "vivência" (Duarte 1998:20). De outro lado, certa evolução do individualismo encontraria no corpo o eixo central da existência pessoal: "esse novo estatuto de uma verdade pelo corpo é inseparável do novo horizonte de especulação sobre a razão que emerge com o empirismo e com o sensualismo" (Duarte \& Giumbelli 1995:103, grifo meu). É importante notar a implicação do corpo na valorização da experiência individual para compreender as transformações no caráter do exercício físico na segunda metade do século XX, tais como são apontadas por Vigarello:

A novidade fundamental das práticas corporais recentes é uma maior importância do íntimo: a atenção dirige-se menos à técnica que às transformações interiores e personalizadas. Referências à saúde sem dúvida, como ocorre há várias décadas, mas afirmação totalmente nova de uma exigência psicológica, modificando as atividades físicas e seus objetivos. A prática consiste sobretudo de um trabalho sobre si, radicalmente afastado dos projetos voluntaristas tradicionais. [...] É como se um novo estado do individualismo estivesse em via de instalação (Vigarello 1982:68).

No caso das academias de ginástica, a gordura e o músculo são operadores capazes de fazer do trabalho do corpo uma produção de si, através de um conjunto de práticas fundado em duas noções: saúde e estética. Mas a relação da saúde com a intimidade ganha aqui contornos particulares. Antes de mais nada, a saúde não se refere a sofrimento, mas a uma ansiedade com o bem-estar. A preocupação com a saúde não significa a relação com a doença ou com o processo de restabelecimento, mas uma "higiene fisiológica" que 
responde a um risco perene. Esforço não para reagir a um estado alterado, mas para impedir a evolução de males que são "silenciosos" e que poderiam irromper a qualquer momento, caso o indivíduo descuidasse da manutenção de seu bem-estar e de sua qualidade de vida. Visto que há também aqui o que Duarte (1998:20) caracteriza como uma responsabilização íntima do indivíduo por seus próprios males, articulada à noção de doença como uma espécie de fantasma, um mal em gestação, elabora-se então uma economia de motivação para a prática de exercícios fundada na culpa (cf. Castro 2003:75). Na academia de ginástica, a preocupação com a própria saúde é um valor, e a quantidade de gordura e suas variações expressam justamente se o indivíduo adere ou não ao imperativo de "se cuidar".

Mas se de uma forma geral o manejo do corpo-metabolismo é uma gerência de si, existe um contraste entre "saúde" e "estética" no que concerne à orientação das práticas corporais. A revista Corpo a Corpo, por exemplo, traz um subtítulo que posiciona os meios de modulação corporal — a atividade física e a regulação alimentar — a meio termo entre a beleza e a saúde: "beleza — fitness — dieta — saúde". Mas na medida em que a saúde assume um estatuto moral, ela ocupa uma posição preponderante nas formas de justificar o exercício físico. O problema coloca-se em relação à "estética", ligada que está à materialidade dos conteúdos corporais. Menos valorizada que a saúde, a estética é um objetivo menos explicitado, e muitas vezes desvelado apenas pela percepção aguçada dos professores: "a gente sabe que todo o pessoal que vem [aqui na academia], mesmo se eles não dizem, eles buscam também a estética".

A preocupação com a forma pode facilmente decair em "corpolatria", voltada à materialidade do corpo e potencialmente danosa à saúde. ${ }^{12}$ Estranha contradição, em que a modulação da aparência física é ao mesmo tempo fundamental nas práticas corporais e alvo de desconfiança. É que a estética não se justifica como um objetivo em si, mas como forma de contribuir para a qualidade de vida e para a saúde por meio da satisfação pessoal. "Bonito é ter saúde", estampa o cartão de visitas de uma academia. Isto não significa, entretanto, uma importância menor, já que a estética está em relação direta com o bem-estar: "não sei dizer se era o meu corpo que me deixava deprimida ou se era a depressão que me fazia descuidar da aparência". E, mais importante, a modulação da forma corporal é mostra de vontade pessoal no agenciamento dos conteúdos corporais: "É muito bom você fazer algo para se cuidar e perceber o resultado concretamente em seu corpo. Melhorou muito meu corpo, fiquei mais musculosa, perdi praticamente toda a gordura e meu corpo está mais formado" (citado em Castro 2003:69; grifos meus).

As práticas corporais das academias de ginástica se estabelecem em um contexto de dois termos - o interior do corpo e a intimidade - entre 
os quais elas cumprem um papel integrador. Como explica um professor de academia: "Vamos pegar o exemplo de um gordinho que está fazendo ginástica; pra ele o que interessa é ficar mais magrinho. Por quê? Se ele tem uma saúde corporal, ele tem uma saúde mental, ele tem uma saúde global..." (citado em Castro 2003:69, grifos meus). Do mesmo modo, a publicidade das academias. Slogan vulgarizado, mens sana in corpore sano aparece como palavra de ordem no impasse entre os dois regimes de verdade do indivíduo moderno. E há quem seja mais explícito: "malhar: a melhor forma de unir corpo e mente".

Esta também parece ser a linha da avaliação corporal. Durante seu desenrolar, junto com as medições, o professor dirige perguntas ao avaliado, traçando uma anamnese de hábitos alimentares e atividades físicas, mas também sondando a motivação, a auto-estima, a percepção do próprio corpo... Ao fim, um bom avaliador engloba esses elementos no plano de exercícios a ser seguido pelo aluno, fixando nas variações da gordura e do músculo as transformações desejáveis no âmbito da saúde e da estética. Assim a avaliação corporal institui a eficácia das práticas corporais, integrando os conteúdos do corpo ao campo de ação da vontade individual — dois domínios da verdade do indivíduo.

Digamos, então, que não são rasas as questões com as quais se defronta o avaliador e seu adipômetro. Se retornarmos ao relato inicial deste artigo em que a aluna abandona a academia após uma avaliação corporal - veremos que esta é uma tarefa delicada, que não se limita a uma leitura do metabolismo corporal, mas implica boa interpretação, abrangendo noções fundamentais para o indivíduo moderno, como a auto-estima e o cuidado de si. A conclusão desfavorável daquele exemplo inicial mostra que a instituição da eficácia das práticas corporais depende do estabelecimento de uma ligação propícia entre os termos que ela mobiliza. Naquela ocasião, o que causou a ruptura não foi o aumento da gordura em si (que não é incomum), mas a forma como o fato foi tratado pelo avaliador, que desastradamente converteu todo o acréscimo da gordura corporal em auto-responsabilização da aluna, manobra que se mostrou insuportável. Este exemplo mostra o papel central da avaliação corporal e indica seus objetivos. Forma de mapear o interior do corpo e os meandros da intimidade para em seguida relacionálos, a avaliação corporal é uma espécie de ritual que evoca a constituição dual do indivíduo e confere às práticas corporais um poder integrador, ainda que cronicamente provisório.

Recebido em 06 de julho de 2005

Aprovado em 09 de novembro de 2006 
Carlos Emanuel Sautchuk é pesquisador associado do grupo Techniques et Culture (CNRS/MNHN, França) e doutorando em antropologia social pela Universidade de Brasília. E-mail: <carlos.sautchuk@gmail.com>.

\section{Notas}

${ }^{1}$ Este é o relato de uma mulher de 28 anos, e foi obtido durante pesquisa de campo realizada no período de maio a julho de 2003 em três academias de ginástica de Brasília. Além disso, o presente escrito é baseado nas publicações sobre beleza e saúde e na literatura especializada em avaliação corporal. Parte das análises aqui contidas deriva das discussões realizadas nos cursos "Pessoa e corpo na antropologia francesa", ministrado pela professora Lia Z. Machado, e "Monografias contemporâneas", dirigido por Mariza Peirano, no Departamento de Antropologia da UnB, em 2003. Sou grato a ambas pelas observações que fizeram às versões iniciais. O artigo foi realizado durante período em que me beneficiei de bolsa de doutorado do CNPq.

${ }^{2}$ A elaboração científica da gordura e das práticas de modulação do corpo não escapou ao interesse dos autores de ficção-científica, como mostra a publicação organizada por Isaac Asimov (1984).

3 Ainda que seja alvo de críticas severas, a fórmula indicada nos manuais (Pollock et alii 1986:215, 225; Heyward e Stolarczyk 2000:9), e que é utilizada nas academias de ginástica, é aquela proposta por William Siri (1961): percentual de gordura corporal $=[(4,95 /$ densidade do corpo $)-4,5] \times 100$.

${ }^{4}$ As academias de ginástica utilizam normalmente as equações universais de Jackson e Pollock (Jackson e Pollock 1978; Pollock et alii 1986) para homens e mulheres (cf. Michelini et alii 2005). Mas existem também equações para "etnias" e faixas de idade específicas. Guedes desenvolveu uma fórmula "brasileira" a partir de experimentos na região Sul do país (cf. Guedes 1994). Para as diferentes fórmulas, ver Costa (2001) e especialmente Heyward e Stolarczyk (2000).

${ }^{5}$ Colaboradores durante alguns anos, Josef Brozek e Ancel Keys têm trajetórias diferentes. O primeiro organizou três encontros internacionais sobre composição corporal e posteriormente dedicou-se notadamente a pesquisas sobre história da psicologia, disciplina de sua primeira formação. Ancel Keys, diretor do Laboratório de Higiene Fisiológica entre 1939 e 1975, foi o autor da K ration (alimentação utilizada pelo exército estadunidense durante a Segunda Guerra Mundial) e sustentou, alguns anos depois, a tese da influência do colesterol nas doenças cardíacas.

${ }^{6}$ A partir dos princípios de Brozek e Keys desenvolveram-se métodos diferentes de avaliação da composição corporal, como a bioimpedância, que distingue a gordura 
do resto do corpo por seu potencial de condutibilidade do impulso elétrico, e não pela densidade. De qualquer modo, o método de referência continua sendo a densitometria, conforme estabelecido por Brozek e Keys (Heyward e Stolarczyk 2000:178).

${ }^{7}$ As críticas à validade deste novo elo são inúmeras. Heyward e Stolarczyk não recomendam "o uso do IMC para estimar a gordura corporal devido ao grande número de erros de predição associados a esse método" (Heyward e Stolarczyk 2000:85). Cf. também Anjos (1992).

${ }^{8}$ No contexto destas críticas, eles lembram, de modo um tanto mordaz, que os vendedores de aves apresentavam um sistema de avaliação da gordura mais completo que o dos médicos, no qual era possível encontrar especificação e classificação objetiva das medidas, de tal modo que se podia avaliar o sabor de um animal ainda vivo (Keys e Brozek 1953:257). Difícil não pensar que este comentário seja também expressão da bricolagem característica da prática científica...

${ }^{9}$ Em um contexto não muito distante do aqui analisado, Roland Barthes também aponta a relação da beleza com o interior do corpo: "Toda a publicidade dos produtos de beleza se fundamenta, também, numa espécie de representação épica do íntimo. As pequenas introduções científicas destinadas a apresentar publicitariamente o produto informam-nos que ele limpa em profundidade, desobstrui em profundidade, alimenta em profundidade, isto é, que, custe o que custar, ele se infiltra (...) Esta abertura pública da interioridade do corpo humano é, de resto, uma característica geral da publicidade dos produtos de toalete" (Barthes 2001:58, 60).

${ }^{10} \mathrm{O}$ trabalho de definição do corpo comporta situações diferentes, notadamente quanto às distinções de gênero. Na impossibilidade de abordar este tema aqui, digamos apenas que de maneira geral os homens tratam de "crescer" (aumentar o volume da musculatura) e enfatizam a prática de exercícios de hipertrofia muscular para tórax e braços; as mulheres buscam "secar" com exercícios "aeróbicos" (que consomem as reservas de gordura), voltados sobretudo para a metade inferior do corpo. Sabino (2000) indica algumas especificidades da produção e do uso das formas corporais masculinas e femininas em academias do Rio de Janeiro.

${ }^{11}$ Conforme as regras da International Federation of Bodybuilding and Fitness, a competição ocorre em torno da evolução da forma interior. Se não, vejamos: "o árbitro deve primeiro avaliar os músculos bíceps, olhando por completo o desenvolvimento de pico do músculo, notando se há ou não uma divisão definida entre as seções anterior e posterior, e continuará a examinar da cabeça aos pés, olhando o desenvolvimento dos antebraços, deltóides, peitorais, peitoral-deltóide unidos, abdominais, coxas, e panturrilhas" (IFBB 2006:52).

${ }^{12}$ É este o teor das críticas ao fisiculturista. Em função do estigma do trabalho do corpo focado exclusivamente em um desenvolvimento físico, modificou-se a denominação das práticas de bodybuilding no Brasil — no lugar de fisiculturismo, simplesmente culturismo. Foi retirada a referência ao "físico", com a pretensão de associar esta prática a um desenvolvimento global do indivíduo. 


\section{Referências bibliográficas}

ANJOS, Luís A. 1992. "Índice de massa corporal (massa corporal/estatura ${ }^{2}$ ) como indicador do estado nutricional de adultos: revisão de literatura". Revista de Saúde Pública, 26(6):431-436.

ASIMOV, Isaac et alii (orgs.). 1984. Coma e emagreça com ficção científica. Rio de Janeiro: Marco Zero [Título original: The science fiction weight-loss book].

BARTHES, Roland. 2001 [1957]. Mitologias. Rio de Janeiro: Bertrand Brasil.

BROZEK, Josef e KEYS, Ancel. 1950. "Limitations of the 'normal' body weight as a criterion of normality". Science, 112:788.

.1951. "Evaluation of leannessfatness in man: norms and interrelationships". British Journal of Nutrition, 5: 194-206.

. 1952. "Body build and body composition". Science, 116:140-142.

CANGUILHEM, Georges. 2002 [1966]. O normal e o patológico. Rio de Janeiro: Forense.

CASTRO, Ana Lúcia de. 2003. Culto ao corpo e sociedade: mídia, estilos de vida e cultura de consumo. São Paulo: Annablume/ Fapesp.

CNRS (Centre National de la Recherche Scientifique). 1981 [1973]. La notion de personne en Afrique Noir. Paris : Ed. du CNRS.

COSTA, Roberto F. 2001. Composição corporal: teoria e prática da avaliação. São Paulo: Manole.

COURTINE, Jean-Jacques. 1995. "Os stakhanovistas do narcisismo: body-building e puritanismo ostentatório na cultura americana do corpo". In: D. B. Sant'Anna (org.), Políticas do corpo. São Paulo: Estação Liberdade. pp. 81-114.

DUARTE, Luis Fernando Dias. 1998. "A investigação antropológica sobre doença, sofrimento e perturbação: uma introdução". In: Luis. F. D. Duarte e O. Leal, Doença, sofrimento, perturbação: perspectivas etnográficas. Rio de Janeiro: Fiocruz. pp. 9-27. . \& GIUMBELLI, Emerson. 1995. "As concepções cristã e moderna da pessoa: paradoxos de uma continuidade". Anuário Antropológico, 93:77-112. Rio de Janeiro: Tempo Brasileiro.

FISCHLER, Claude. 1987. "La symbolique du gros". Communications, 46:255-278. 1995. "Obeso benigno, obeso maligno". In: D. B. Sant'Anna (org.), Políticas do corpo. São Paulo: Estação Liberdade. pp. 69-80.

FOUCAULT, Michel. 1972. Naissance de la clinique: une archéologie du regard médical. Paris: PUF.

FUSSEL, Sam. 1997. "Bodybuilder americanus". In: L. Goldstein (org.) The male body. Michigan: University of Michigan. pp. 43-60.

GIL, José. 1997. Metamorfoses do corpo. Lisboa: Relógio D'Água.

GODELIER, Maurice \& PANOFF Michel (orgs.). 1998. La production du corps: approches anthropologiques et historiques. Amsterdam : Éditions des Archives Contemporains.

GUEDES, Dartagnan P. 1994. Composição corporal: princípios, técnicas e aplicações. Londrina: Associação dos Professores de Educação Física. e GUEDES, Joana. 1998. Controle do peso corporal: composição corporal, atividade física e nutrição. Londrina: Midiograf.

HÉRITIER, Françoise \& XANTHAKOU, Margarita (orgs.). 2004. Corps et affects. Paris: Odile Jacob.

HEYWARD, Vivian e STOLARCZYK, Lisa. 2000 [1996]. Avaliação da composição corporal aplicada. São Paulo: Manole. 
IFBB - International Federation of Bodybuilding and Fitness. 2006. IFBB rules: bodybuilding, fitness, bodyfitness. Quebec: IFBB.

JACKSON, A. S. \& POLLOCK, M. 1978. "Generalized equations for predicting body density of men". British Journal of Nutrition, 40:497-504.

KEYS, Ancel e BROZEK, Josef. 1953. "Body fat in adult man". Physiological Reviews, 33(3):245-325.

KEYS, Ancel et alii. 1971. "Indices of relative weight and obesity". Journal of Chronic Diseases, 25:329-343.

LATOUR, Bruno. 1993. La clef de Berlin et autres leçons d'un amateur de sciences. Paris: La Decouverte. 1994 [1991]. Jamais fomos modernos. Rio de Janeiro: Editora 34. 2001. "Referência circulante: amostragem do solo da floresta amazônica". In: A esperança de Pandora. Bauru: EDUSC. pp. 39-96.

LE BRETON, David. 1990. Anthropologie du corps et modernité. Paris: PUF.

LIVI, Carlo. 1897. "Lindice ponderale o rapporto tra la statura e il peso". Atti della Società Romana di Antropologia, 5:125-153.

MAREY, Étienne-Jules. 1994 [1894] . Le mouvement. Nîmes: J. Chambon.

MATIEGKA, Jindrich. 1921. "The testing of physical efficiency". American Journal of Physical Anthropology, IV(3):223-230.

MICHELINI, Marcelo et alii. 2005. "Métodos mais utilizados em academias para avaliação de composição corporal". Nutrição em pauta, XIII (71). Disponível em : www.nutriçãoempauta. com.br. Consultado em 18/04/2006.

POCIELLO, Christian. 1999. La science en mouvements: Étienne Marey et Georges Demenÿ: 1870-1920. Paris: PUF.

POLHEMUS, Ted (org.). 1978. Social aspects of the human body. Middlesex: Penguin.
POLLOCK, Michael et alii. 1986. Exercícios na saúde e na doença: avaliação e prescrição para prevenção e reabilitação. Rio de Janeiro: MEDSI.

QUETELET, Adolph. 1870. Anthropométrie ou mesure des différentes facultés de l'homme. Bruxelas: C. Muquardt.

RICHER, Paul. 1890. "Du rôle de la graisse dans la conformation extérieure du corps humain". Nouvelle Iconographie de la Salpetrière, 3:20-26.

SABINO, Cesar. 2000. "Musculação: expansão e manutenção da masculinidade". In: Miriam Goldenberg (org.), Os novos desejos: das academias de musculação às agências de encontros. Rio de Janeiro: Record. pp. 65-104.

SHELDON, William. 1940. The varieties of human physique: an introduction to constitutional psychology. New York: Harper.

SIRI, William. 1961. "Body composition from fluid spaces and density: analysis of methods." In: J. Brozek e A. Henschel (orgs.), Techniques for measuring body composition. Washington: Nat. Acad. Sci-Nat. Res. Council. pp. 223-224.

STEARNS, Peter. 2002 [1997]. Fat history: bodies and beauty in the modern West. New York and London: New York University Press.

VAGUE, Jean. 1947. "La différentiation sexuelle: facteur déterminant des formes de l'obésité". La Presse Médicale, 30:339-40.

VIGARELLO, Georges. 1982. "Les vertiges de l'intime". Esprit, 2:68-78.

WHO - World Health Organization. 1995. Physical Status: the use and interpretation of anthropometry. Genebra: WHO Technical Report Series. 2000. Obesity: preventing and managing the global epidemic. Genebra: WHO Technical Report Series. 
Resumo

A partir de pesquisa etnográfica e bibliográfica, o presente artigo trata da gordura nas academias de ginástica, enfocando questões relativas ao corpo e à pessoa. A análise da avaliação corporal evidencia os termos de uma produção científica que elabora o corpo como um metabolismo caracterizado pelo risco e pela maleabilidade. São os conteúdos corporais que estão em jogo, de modo que o ideal estético não é a magreza, mas a "definição" do corpo, fruto da sobreposição da gordura pelo músculo. A busca da saúde caracteriza-se pela gerência constante do risco inerente ao balanço destes componentes. Beleza e saúde são formas de cuidar de si - imperativo caro ao individualismo contemporâneo - através do manejo dos conteúdos corporais. Assim, a avaliação corporal delineia os elementos internos e os aspectos da intimidade, e dota as práticas corporais da capacidade de empreender um engajamento entre eles.

Palavras-chave: Antropologia do Corpo, Antropologia da Saúde, Antropometria, Beleza.

\section{Abstract}

Based on both ethnographic and bibliographic research, the present article examines the subject of fat in gymnastic academies, focusing on issues relating to the body and the person. An analysis of body evaluation evinces the terms of a scientific production that configures the body as a metabolism subject to risk and malleability. What is at stake are body contents, where the aesthetic ideal is not thinness, but the 'toning' of the body, the result of replacing fat with muscle mass. The search for beauty involves constant management of the risk inherent in balancing these components. Beauty and health are forms of self-care - an imperative central to contemporary individualism — through the management of body contents. Thus, body evaluation delineates internal elements and aspects of intimacy, and endows bodily practices with the capacity to stimulate an interaction between them.

Key words: Anthropology of the Body, Anthropology of Health, Anthropometry, Beauty. 